\title{
Nomogram for Predicting Risk of Digestive Carcinoma Among Patients with Type 2 Diabetes
}

This article was published in the following Dove Press journal:

Diabetes, Metabolic Syndrome and Obesity: Targets and Therapy

\section{Lu-Huai Feng (1D \\ Kun-Peng Bu' \\ Shuang Ren' \\ Zhenhua Yang ${ }^{2}$ \\ Bi-Xun Li ${ }^{1}$ \\ Cheng-En Deng ${ }^{3}$}

'Department of Comprehensive Internal Medicine, The Affiliated Tumor Hospital of Guangxi Medical University, Nanning, People's Republic of China; ${ }^{2}$ Department of Nephrology, The First Affiliated Hospital of Guangxi Medical University, Nanning, People's Republic of China; ${ }^{3}$ Department of Urology, The Affiliated Tumor Hospital of Guangxi Medical University, Nanning, People's Republic of China
Correspondence: Cheng-En Deng Department of Urology, The Affiliated Tumor Hospital of Guangxi Medical University, Nanning 53002I, Guangxi Zhuang Autonomous Region, People's

Republic of China

Tel +86 18775391817

Fax +86 77I-57I9573

Email dengchengen66@126.com

Bi-Xun Li

Department of Comprehensive Internal Medicine, The Affiliated Tumor Hospital of Guangxi Medical University, Nanning 53002I, Guangxi Zhuang Autonomous Region, People's Republic of China

Tel +86 I8977I00069

Fax +86 77I-57I9573

Email libixun@126.com
Purpose: Digestive carcinomas remain a major health burden worldwide and are closely related to type 2 diabetes. The aim of this study was to develop and validate a digestive carcinoma risk prediction model to identify high-risk individuals among those with type 2 diabetes.

Patients and Methods: The prediction model was developed in a primary cohort that consisted of 655 patients with type 2 diabetes. Data were collected from November 2013 to December 2018. Clinical parameters and demographic characteristics were analyzed by logistic regression to develop a model to predict the risk of digestive carcinomas; then, a nomogram was constructed. The performance of the nomogram was assessed with respect to calibration, discrimination, and clinical usefulness. The results were internally validated by a bootstrapping procedure. The independent validation cohort consisted of 275 patients from January 2019 to December 2019.

Results: Predictors in the prediction nomogram included sex, age, insulin use, and body mass index. The model showed good discrimination (C-index 0.747 [95\% CI, 0.718-0.791]) and calibration (Hosmer-Lemeshow test $\mathrm{P}=0.541$ ). The nomogram showed similar discrimination in the validation cohort (C-index 0.706 [95\% CI, 0.682-0.755]) and good calibration (Hosmer-Lemeshow test $\mathrm{P}=0.418$ ). Decision curve analysis demonstrated that the nomogram would be clinically useful.

Conclusion: We developed a low-cost and low-risk model based on clinical and demographic parameters to help identify patients with type 2 diabetes who might benefit from digestive cancer screening.

Keywords: type 2 diabetes, digestive cancer, prediction, demographic

\section{Introduction}

Both diabetes and cancer are prevalent diseases whose incidence is increasing globally and which seriously threaten human health. ${ }^{1,2}$ More attention is paid to complications of diabetes such as cardiovascular disease, blindness, kidney failure, and lower limb amputation, and the relationship between diabetes and cancer is rarely considered. However, a meta-analytic study in 2009 by Vigneri et al showed that the risk of several cancer types (including cancers of the pancreas, liver, breast, colorectal, urinary tract, and female reproductive organs) was increased in diabetic patients, with a moderate increase in mortality. ${ }^{3}$ There is now growing recognition that there may be a meaningful association between diabetes and cancer, ${ }^{4}$ although the potential biological links between the two conditions are incompletely understood. ${ }^{1}$

Digestive carcinomas remain a major health burden worldwide, especially in Asia. ${ }^{5}$ Studies show that the incidence of digestive carcinomas and type 2 diabetes has 
increased exponentially in the past decade. ${ }^{6,7}$ Accumulating evidence indicates that digestive carcinomas are closely associated with type 2 diabetes, ${ }^{8,9}$ especially primary liver cancer, pancreatic cancer, and colorectal cancer. ${ }^{10-13}$ Epidemiological data suggest that diabetes increases the relative risk of digestive cancers more than twofold, ${ }^{1}$ and type 2 diabetes mellitus is associated with more aggressive digestive tract cancers. ${ }^{14}$ Universal screening using potential biomarkers such as cancer antigen 19-9, carcinoembryonic antigens, or clinical tests (eg, computed tomography, endoscopic ultrasound, or magnetic resonance imaging) is not feasible, ${ }^{15-17}$ as the existing biomarkers have limited diagnostic accuracy. Therefore, there is an urgent clinical need for novel prediction models and screening methods that are both efficient and cost-effective for the detection of asymptomatic cases. ${ }^{18}$

The nomogram is considered a reliable tool that can be used to create a simple intuitive graph of a statistical predictive model that quantifies the risk of a clinical event. ${ }^{19,20}$ In this study, we aimed to identify a combination of variables that would enable highly accurate prediction of digestive carcinomas in patients with type 2 diabetes. A nomogram for predicting the risk of digestive carcinomas was then constructed to support recommendations based on physical examination.

\section{Patients and Methods}

This retrospective study was performed with approval from the Ethics Committee of the Affiliated Tumor Hospital of Guangxi Medical University (approval no. LW2020010). As this was a retrospective analysis of anonymized clinically obtained data and all patient identifiers were removed, there was no need for patients to sign the informed consent. This study was conducted in accordance with the tenets of the Declaration of Helsinki.

\section{Patients}

The primary cohort of this study comprised 655 patients in our hospital from November 2013 to December 2018 who had been diagnosed with type 2 diabetes. From January 2019 to December 2019, an independent validation cohort consisting of 275 consecutive patients was screened using the same criteria as the primary cohort. The proportions of patients with digestive carcinoma were $37.8 \%$ and $40.7 \%$ in the primary and validation cohorts, respectively. The inclusion criteria were: (1) a clear diagnosis of type 2 diabetes before the diagnosis of carcinoma; and (2) clinical pathology that supported the diagnosis of carcinoma. Exclusion criteria were: (1) the presence of two or more cancer types; (2) pancreatic cancers diagnosed within 5 years after the type 2 diabetes diagnosis (owing to reverse causation ${ }^{1,21}$ ); (3) incomplete patient data.

\section{Data Collection}

Participants were divided into digestive carcinoma and nondigestive carcinoma groups; approximately $20 \%$ of the latter group had tumors of other systems, including lung, breast, and cervical cancers. Clinical parameters and demographic data were collected, including age, sex, diabetes duration (months), comorbidities (hypertension, coronary artery disease, cerebrovascular disease), use of blood glucoselowering drugs, history of smoking, body mass index (BMI), and family history of cancer. Diabetes duration was defined as the time from first diagnosis of type 2 diabetes to the diagnosis of malignancy; the diagnosis of type 2 diabetes in our institution complies with World Health Organization criteria: ${ }^{22}$ (1) diabetes symptoms plus random blood glucose $\geq 11.1 \mathrm{mmol} / \mathrm{L}$, or (2) fasting blood glucose $\geq 7.0 \mathrm{mmol} / \mathrm{L}$, or (3) 2-hour blood glucose oral glucose tolerance test $\geq 11.1$ $\mathrm{mmol} / \mathrm{L}$. Blood glucose-lowering drugs included insulin, thiazolidinediones, alpha-glucosidase inhibitors, and sulfonylureas. Cerebrovascular disease was defined as transient ischemic attack, stroke, history of carotid artery stent, or cerebral hemorrhage. Coronary artery disease was defined as a history of myocardial infarction, coronary artery bypass grafting, or percutaneous coronary intervention. Family history of cancer was defined as more than one relative with first-degree carcinoma. Smoking was defined as the number of packs of cigarettes ( 1 pack $=20$ cigarettes) smoked per day in a year, including current smokers and ex-smokers. ${ }^{23}$ Overweight was defined as $24 \leq \mathrm{BMI}<28 \mathrm{~kg} / \mathrm{m}^{2}$, and obese was defined as $B M I \geq 28 \mathrm{~kg} / \mathrm{m}^{2}$, as is standard for the Chinese population.

\section{Statistical Analysis}

\section{Construction of the Nomogram}

The statistical analyses were performed and graphics were produced with SPSS version 26.0 (IBM Corp, Armonk, NY, USA) and R software (the rms package of the R library) version 3.6.2 (https://www.r-project.org/). For all analyses, $\mathrm{P}<0.05$ was considered to be statistically significant and all tests were two-tailed unless otherwise indicated. For continuous variables, data are presented as median and interquartile range $\left(M\left(P_{25}, P_{75}\right)\right)$ or mean \pm standard deviation. Categorical variables are presented as whole numbers and proportions. Differences between groups were assessed using the chi-squared test or Wilcoxon rank-sum test with 
SPSS. The significance of each variable in the primary cohort was assessed by univariate logistic regression to investigate the independent risk factors for digestive cancers. All variables with $\mathrm{P}<0.05$ in the univariate logistic analyses were further assessed by multivariable logistic regression with backward step-wise selection, using the likelihood ratio test with Akaike's information criterion as the stopping rule. ${ }^{24}$ To provide the clinician with a quantitative tool to evaluate digestive carcinoma risk in patients with type 2 diabetes, a nomogram for digestive carcinoma risk was constructed on the basis of the results from the final multivariable logistic regression using the $\mathrm{R}$ software. ${ }^{20}$

\section{Performance of the Nomogram in the Primary Cohort}

Calibration curves were plotted to calibrate the nomogram. ${ }^{20}$ The C-index was used to evaluate discriminative ability, ranging from 0.5 (absence of discrimination) to 1 (perfect discrimination). ${ }^{25}$ In addition, the nomogram was subjected to 1000 bootstrap resamples for internal validation to assess predictive accuracies. ${ }^{26}$

\section{External Validation of the Nomogram}

The performance of the nomogram was tested in the validation cohort. The logistic regression formula was developed based on the primary cohort and applied to all patients in the validation cohort, and total points were calculated for each patient. Logistic regression of the validation cohort was performed using total points as a factor. The $\mathrm{C}$-index and calibration curve were derived on the basis of the regression analysis.

\section{Clinical Use of the Nomogram}

Decision curve analysis was conducted using the R library rmda package to determine the clinical usefulness of the nomogram by quantifying the net benefit at different threshold probabilities in the primary dataset. The net benefit was calculated by subtracting the proportion of false positives from the proportion of true positives and weighting by the relative harm of forgoing treatment compared with the negative consequences of an unnecessary treatment. ${ }^{27}$

\section{Results}

\section{Characteristics of Patients in the Primary and Validation Cohorts}

A total of 930 patients were enrolled in our study, with 655 and 275 patients assigned to the primary and validation cohorts, respectively. Table 1 shows the patient characteristics
Table I Characteristics of Patients in the Primary and Validation Cohorts

\begin{tabular}{|c|c|c|c|}
\hline Variable & $\begin{array}{l}\text { Primary } \\
\text { Cohort }\end{array}$ & $\begin{array}{l}\text { Validation } \\
\text { Cohort }\end{array}$ & P-value \\
\hline Age, years & $59(53,65)$ & $61(54,66)$ & 0.054 \\
\hline \multicolumn{4}{|l|}{ Comorbidities } \\
\hline Hypertension, yes, N (\%) & $260(39.7 \%)$ & 99 (36.0\%) & 0.291 \\
\hline $\begin{array}{l}\text { Coronary artery disease, yes, } \\
N(\%)\end{array}$ & $156(23.8 \%)$ & $55(20.0 \%)$ & 0.205 \\
\hline $\begin{array}{l}\text { Cerebrovascular disease, yes, } \\
N(\%)\end{array}$ & $126(19.2 \%)$ & $48(17.5 \%)$ & 0.525 \\
\hline $\begin{array}{l}\text { Family history of carcinomas, } \\
\text { yes, } N(\%)\end{array}$ & 89 (13.6\%) & $34(12.4 \%)$ & 0.615 \\
\hline Diabetes duration, month & $69(24,120)$ & $81(27,135)$ & 0.962 \\
\hline \multicolumn{4}{|l|}{ Sex, N (\%) } \\
\hline Male & $380(58.0 \%)$ & $164(59.6 \%)$ & 0.647 \\
\hline Female & 275 (42.0\%) & III (40.4\%) & \\
\hline \multicolumn{4}{|l|}{ Blood glucose-lowering drugs } \\
\hline Insulin, yes, N (\%) & $125(19.1 \%)$ & $40(14.5 \%)$ & 0.098 \\
\hline Thiazolidinediones, yes, N (\%) & $8(1.2 \%)$ & $8(2.9 \%)$ & 0.071 \\
\hline $\begin{array}{l}\text { Alpha glucosidase inhibitors, } \\
\text { yes, } N(\%)\end{array}$ & $72(11.0 \%)$ & $36(13.1 \%)$ & 0.362 \\
\hline Sulfonylureas, yes, N (\%) & $85(13.0 \%)$ & $44(16.0 \%)$ & 0.224 \\
\hline Metformin, yes, $\mathrm{N}(\%)$ & $109(16.6 \%)$ & $57(20.7 \%)$ & 0.138 \\
\hline $\begin{array}{l}\text { Combination of oral drugs and } \\
\text { insulin, yes, } N(\%)\end{array}$ & $26(4.0 \%)$ & $8(2.9 \%)$ & 0.432 \\
\hline $\begin{array}{l}\text { Combination of oral drugs, yes, } \\
N(\%)\end{array}$ & $66(10.1 \%)$ & $42(15.3 \%)$ & 0.024 \\
\hline Smoking, yes, N (\%) & $223(34.0 \%)$ & $95(34.5 \%)$ & 0.883 \\
\hline \multicolumn{4}{|l|}{ BMI, N (\%) } \\
\hline Normal & $385(58.8 \%)$ & $145(52.7 \%)$ & 0.234 \\
\hline Overweight & $211(32.2 \%)$ & $101(36.7 \%)$ & \\
\hline Obese & $59(9.0 \%)$ & $29(10.5 \%)$ & \\
\hline Digestive carcinoma type, $\mathrm{N}(\%)$ & & & 0.620 \\
\hline Esophageal cancer & $9(1.4 \%)$ & $7(2.5 \%)$ & \\
\hline Gastric cancer & $23(3.5 \%)$ & II (4.0\%) & \\
\hline Primary liver cancer & $114(17.4)$ & $45(16.4 \%)$ & \\
\hline Pancreatic cancer & $7(1.1 \%)$ & $5(1.8 \%)$ & \\
\hline Colorectal cancer & 95 (14.5\%) & $44(16.0 \%)$ & \\
\hline
\end{tabular}

Notes: $24 \leq \mathrm{BMl}<28 \mathrm{~kg} / \mathrm{m}^{2}$ is defined as overweight and $\geq 28 \mathrm{~kg} / \mathrm{m}^{2}$ is defined as obese for the Chinese population.

Abbreviation: BMI, body mass index.

by cohort. The baseline clinical characteristics were similar between the two cohorts, with digestive carcinoma proportions of $37.8 \%$ and $40.7 \%$ in the primary and validation cohorts, respectively $(\mathrm{P}=0.061)$.

\section{Construction of the Nomogram}

The results of the univariate logistic analysis are presented in Table 2. According to the multivariate analysis, with results reported as odds ratio (95\% CI), age (1.021 [1.002-1.040]), 
Table 2 Univariate Logistic Regression Analysis of Factors Relating to Digestive Carcinomas in the Primary Cohort

\begin{tabular}{|l|l|l|l|}
\hline Variable & $\boldsymbol{\beta}$ & P-value & $\begin{array}{l}\text { Odds Ratio (95\% } \\
\text { Cl) }\end{array}$ \\
\hline Sex & -1.916 & $<0.00 \mathrm{I}$ & $0.147(0.099-0.218)$ \\
Age & -0.548 & 0.006 & $1.024(1.007-1.042)$ \\
\hline Comorbidities & & & \\
Hypertension & 0.276 & 0.089 & $1.318(0.958-1.814)$ \\
Coronary artery disease & 0.315 & 0.093 & $1.370(0.949-1.977)$ \\
Cerebrovascular disease & 0.365 & 0.070 & $1.440(0.971-2.138)$ \\
Diabetes duration & 0.004 & 0.004 & $1.004(1.001-1.006)$ \\
Family history of carcinomas & 0.132 & 0.572 & $1.141(0.722-1.805)$ \\
Smoking & 0.729 & $<0.001$ & $2.074(1.487-2.893)$ \\
BMI & -0.462 & $<0.001$ & $0.630(0.486-0.816)$ \\
\hline Use of blood glucose-lowering & & & \\
drugs & & & \\
Insulin & 0.706 & $<0.001$ & $2.207(1.366-3.006)$ \\
Thiazolidinediones & -0.557 & 0.497 & $0.573(0.115-2.861)$ \\
Alpha glucosidase inhibitors & -0.026 & 0.921 & $0.975(0.586-1.622)$ \\
Sulfonylureas & -0.248 & 0.318 & $0.780(0.479-1.270)$ \\
Metformin & -0.045 & 0.838 & $0.956(0.623-1.468)$ \\
Combination of oral drugs & 0.572 & 0.154 & 1.77 (0.807-3.886) \\
and insulin & & & \\
Combination of oral drugs & -0.238 & 0.392 & $0.788(0.458-1.359)$ \\
\hline
\end{tabular}

Abbreviation: BMI, body mass index.

sex (0.124 [0.078-0.198]), insulin (1.806 [1.162-2.806]), and BMI $(0.630$ [0.486-0.816]) were independently associated with digestive carcinoma (Table 3). The model that incorporated the above independent predictors was developed as the nomogram (Figure 1).

\section{Performance of the Nomogram in the Primary Cohort}

The calibration curve showed that the risk of digestive carcinoma predicted by the nomogram agreed well with the actual probabilities in the primary cohort (Figure 2). The HosmerLemeshow test yielded a nonsignificant statistic $(\mathrm{P}=0.541)$, which suggested that our model was well calibrated with no

Table 3 Multivariate Logistic Regression Analysis of Factors Relating to Digestive Carcinomas in the Primary Cohort

\begin{tabular}{|l|l|l|l|}
\hline Variable & $\boldsymbol{\beta}$ & P-value & Odds Ratio (95\% Cl) \\
\hline Sex & -2.089 & $<0.001$ & $0.124(0.078-0.198)$ \\
Age & 0.021 & 0.029 & $1.021(1.002-1.040)$ \\
Insulin & 0.591 & 0.009 & $1.806(1.162-2.806)$ \\
Smoking & -0.393 & 0.065 & $0.675(0.444-1.025)$ \\
BMI & -0.364 & 0.014 & $0.695(0.521-0.928)$ \\
Diabetes duration & 0.002 & 0.122 & $1.002(0.999-1.005)$ \\
\hline
\end{tabular}

Notes: Hosmer-Lemeshow test: $\chi^{2}=6.962, P=0.541$. C-index: 0.747 (0.718-0.791). departure from perfect fitting. The $\mathrm{C}$-index for the prediction nomogram was 0.747 (95\% CI $0.718-0.791)$ for the primary cohort, corrected to 0.734 via bootstrapping validation $(B=1000)$, which suggested good discrimination by our model.

\section{External Validation of the Nomogram in the Validation Cohort}

Good calibration and discriminative ability were also observed for the nomogram in the validation cohort (Figure 3). The Hosmer-Lemeshow test yielded a nonsignificant statistic ( $\mathrm{P}=0.418$ ), and the $\mathrm{C}$-index of the nomogram for the risk of digestive cancers was 0.706 (95\% CI 0.682-0.755).

\section{Clinical Use of the Model}

The results of the decision curve analysis for the nomogram are presented in Figure 4. This graphically shows the clinical usefulness of the nomogram based on a continuum of potential thresholds for digestive cancer risk (x-axis) and the net benefit of using the nomogram to stratify patients by risk (y-axis), assuming that no patient will have digestive cancer. In this analysis, the final decision curve showed that for a threshold probability between $10 \%$ and $65 \%$, the model had positive net benefit. For example, if the personal threshold probability of a patient was $30 \%$ (ie, the patient would opt for further detailed screening if his risk of digestive cancer were $30-65 \%$ ), the net benefit would be 0.2 when using the nomogram to decide whether to conduct further detailed screening, with added benefit compared with screen-all or screen-none schemes.

\section{Discussion}

Early detection and treatment of digestive cancers are important to improve patient quality of life. In this study, we developed and validated a simple intuitive statistical predictive model to quantify the risk of digestive carcinoma, which could support clinicians and patients when making screening decisions for patients with type 2 diabetes. The easy-to-use nomogram incorporates four clinical risk factors (sex, age, insulin use, and BMI) to facilitate risk prediction for digestive carcinoma in patients with type 2 diabetes. The prediction model for digestive carcinoma showed good discrimination and calibration in type 2 diabetes; the C-index was 0.747 (0.734 via bootstrapping validation) and the HosmerLemeshow test yielded a nonsignificant statistic $(\mathrm{P}=0.541)$ in the primary cohort, with a similar result in the validation cohort.

Although type 2 diabetes and cancer share several risk factors, including obesity, aging, unhealthy food, and 
Points

$\begin{array}{lllllllllll}0 & 10 & 20 & 30 & 40 & 50 & 60 & 70 & 80 & 90 & 100\end{array}$

Points

Sex

Age

Insulin

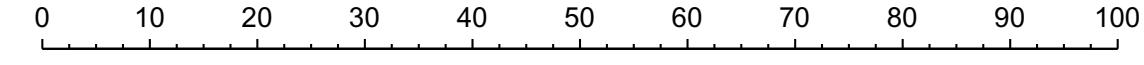

\begin{tabular}{|c|c|c|c|c|c|c|c|}
\hline \multirow{2}{*}{ Age } & & & & & & & \\
\hline & 30 & 40 & 50 & 60 & 70 & 80 & 90 \\
\hline Insulin & & \multicolumn{6}{|c|}{ yes } \\
\hline & no & & & & & & \\
\hline
\end{tabular}

BMI

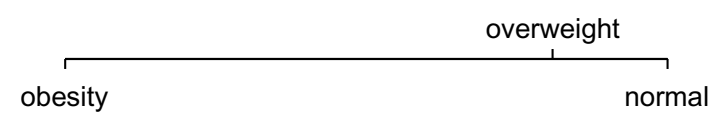

Total Points

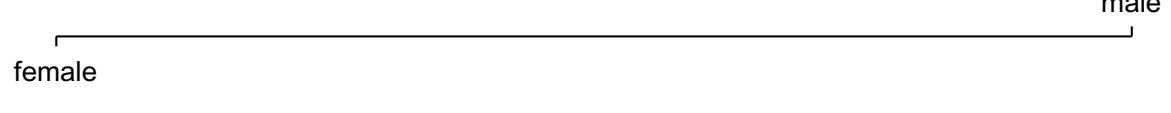

male

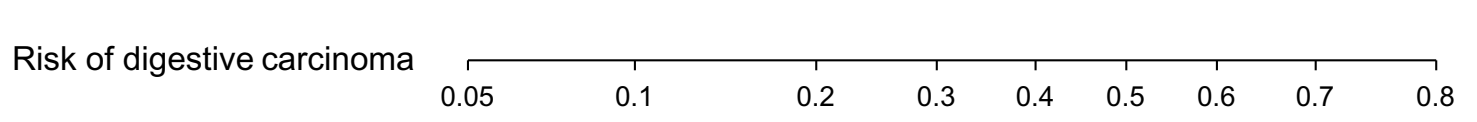

Figure I Nomogram developed on the basis of the primary cohort, with sex, age, insulin use, and BMI incorporated.

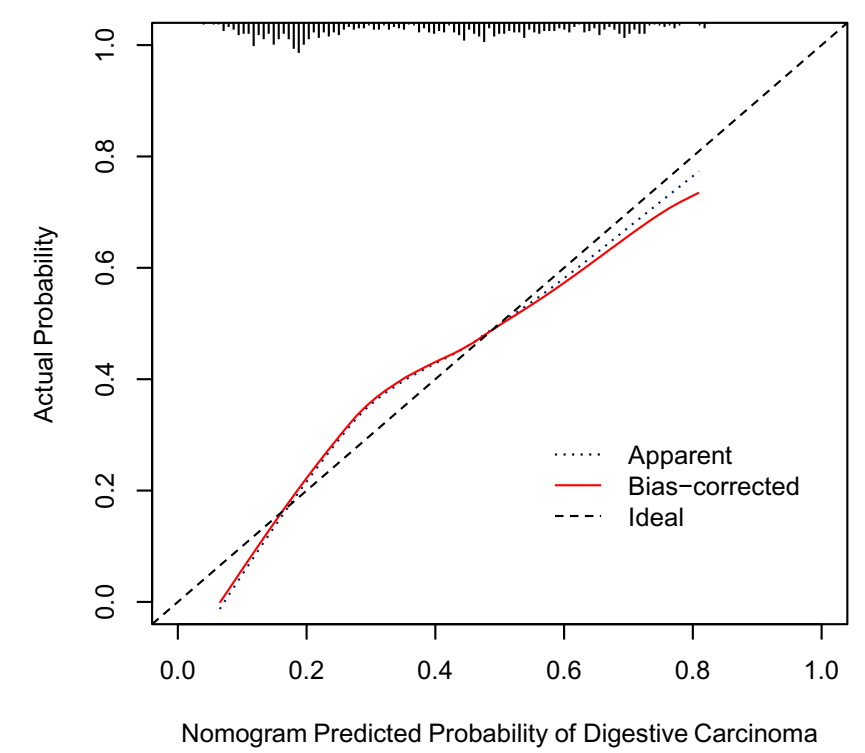

Figure 2 Calibration curves for the nomogram in the primary cohort. The blue dotted line represents the entire cohort $(n=655)$, and the red solid line is the result after bias-correction by bootstrapping ( 1000 repetitions), indicating nomogram performance.

physical inactivity, ${ }^{1}$ an association between type 2 diabetes and the risk of digestive carcinoma is biologically plausible based on the findings of previous studies. ${ }^{1,28,29}$ To best of our knowledge, few studies have developed or validated risk prediction models for digestive carcinomas in patients with type 2 diabetes. In 2016, Boursi et $\mathrm{al}^{30}$ developed

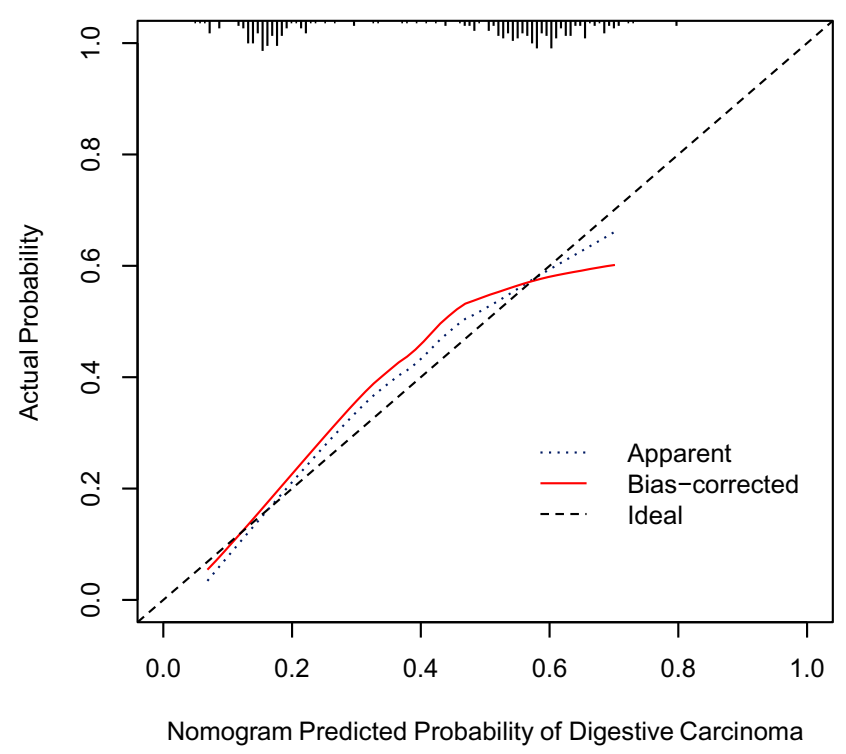

Figure 3 Calibration curves for the nomogram in the validation cohort. The blue dotted line represents the entire cohort $(n=275)$, and the red solid line is the result after bias-correction by bootstrapping ( 1000 repetitions), indicating nomogram performance.

a model to assess risk of pancreatic cancer among patients with new-onset diabetes, which yielded a good area under the curve $(0.82)$. Hsieh et $\mathrm{al}^{31,32}$ used artificial neural network models to assess risk of colorectal and pancreatic cancer among patients with type 2 diabetes mellitus. However, our study differs from previous development 


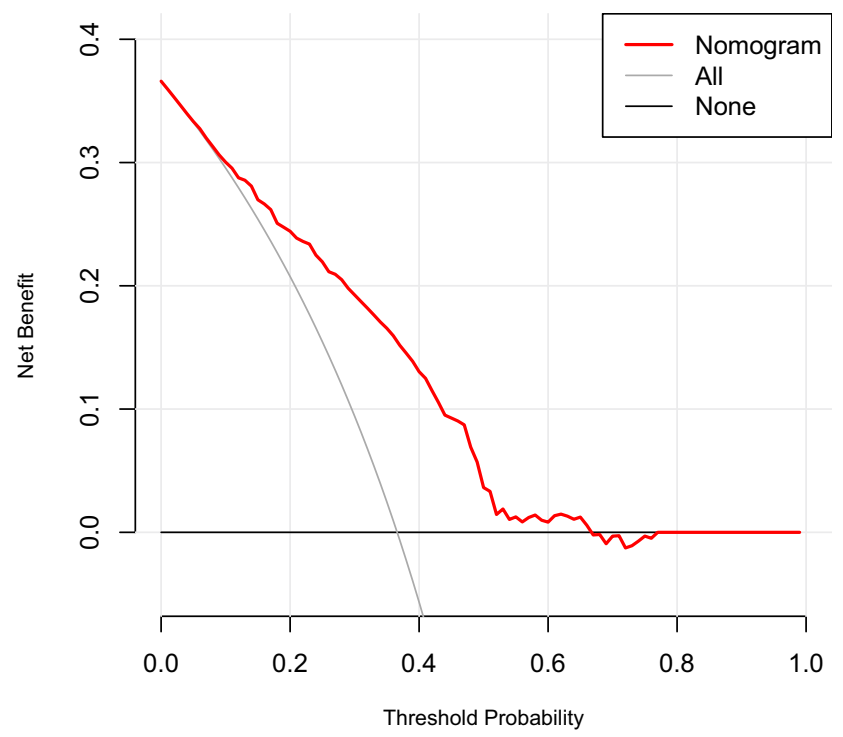

Figure 4 Decision curve analysis for the nomogram.

and validation work as it involves a comprehensive evaluation, whereas other studies developed a single disease prediction model for type 2 diabetes mellitus.

Furthermore, obesity is generally thought to be associated with the development of many cancers, especially digestive system malignancies, ${ }^{33}$ which contradicts our results. However, although a meta-analysis by Dong et $\mathrm{al}^{34}$ showed that it is more appropriate to use abdominal obesity to measure the relationship between cancer and obesity, our study could only measure obesity by BMI owing to its retrospective nature. On the other hand, research on the relationship between obesity and digestive cancer was mainly carried out on populations from Western countries. ${ }^{35,36}$ Eastern and Western countries have very different dietary habits, and there are also certain differences in body shape. This may have led to the conflicts between our results and those of other studies.

In China, $36.4 \%$ of cancer-related deaths involve digestive tract cancers (stomach, liver, and esophageal cancers), which have relatively poorer prognoses. ${ }^{37}$ Currently, surgery and/or chemotherapy are the most effective treatment for digestive carcinomas. ${ }^{38}$ Some cancers, including primary liver cancer, colorectal cancer, and stomach cancer, can be clinically cured by surgery in the early stages. ${ }^{38}$ However, most patients with digestive carcinomas are diagnosed at advanced stages of the disease, and the overall 5-year survival rate for these patients is low. ${ }^{39-41}$ There is already evidence that diabetes (mainly type 2) and digestive cancers are closely related; ${ }^{1,14}$ therefore, the implementation of population-based screening programs may significantly reduce the mortality and incidence of digestive cancers in patients with type 2 diabetes.
However, although screening for cancer has many benefits, there are also potential risks. Overscreening may lead to overtreatment and cause more harm than gain. Gastrointestinal endoscopy is an important and painless test for digestive tumors, but it also can delay patient recovery and discharge time and increases the risk of cardiopulmonary complications, which are understood to account for $\sim 50 \%$ of mortality and $\sim 60 \%$ of morbidity associated with upper gastrointestinal endoscopy. ${ }^{42,43}$ Conducting mass digestive carcinoma screening of all patients with type 2 diabetes patients using costly and/or invasive tests would not be an efficient approach, because the vast majority of these patients do not have digestive carcinomas. Our prediction model provides a low-cost and low-risk solution to this problem by identifying high-risk individuals for definitive diagnostic testing. This easy-touse scoring system could be used to perform an individualized prediction of the risk of digestive cancers.

The most important and final argument for the use of the nomogram is based on individual needs for additional investigation or care. However, despite better risk prediction performance, calibration, and discrimination, the nomogram could not capture the clinical consequences of a particular level of discrimination or degree of miscalibration. ${ }^{44-46}$ Therefore, to justify its clinical use, decision curve analysis was applied to assess whether the nomogram-based decisions would be helpful. This novel method offers insight into clinical consequences on the basis of a threshold probability from which net benefit can be derived. ${ }^{44}$ The decision curve showed that for a threshold probability between $10 \%$ and $65 \%$, the model would result in a positive net benefit. For example, if the personal threshold probability of a patient was $30 \%$ (ie, the patient would opt for further detailed screening if his risk of digestive cancer were $30-65 \%$ ), the net benefit would be 0.2 when using the nomogram to decide whether to conduct further detailed screening, with added benefit compared with a screen-all or screen-none scheme.

The nomogram developed here has certain limitations. First, our prediction nomogram was constructed retrospectively; several known risk factors for digestive cancers, such as race, exercise, and dietary pattern, were not included in the database; and the sample size was small. As such, some analyses may have been limited, and the use of the model may be restricted to certain regions and races. However, the current nomogram model was shown to have excellent predictive power. Second, the model was not intended to be a definitive diagnostic test but rather to identify type 2 diabetes patients at high risk for digestive 
cancers. Third, a key limitation of this work is that all digestive cancers were combined, when they are in fact very different cancers and have different risks associated with type 2 diabetes. However, its sole reliance on demographic information means that this model could be easily applied in practice to virtually every patient with type 2 diabetes mellitus with negligible cost or risk. Further data collection, wider geographic recruitment, and incorporation of positron emission tomography results and molecular factors could improve the model for future use.

\section{Conclusions}

In this work, we have developed a low-cost and low-risk model based on clinical and demographic parameters to identify patients with type 2 diabetes who might benefit from digestive cancer screening. Both physicians and type 2 diabetes patients could perform individualized prediction of the risk of digestive cancers with this easy-to-use scoring system.

\section{Funding}

This research did not receive any specific grant from funding agencies in the public, commercial, or not-forprofit sectors.

\section{Disclosure}

The authors declare that there are no conflicts of interest related to this work.

\section{References}

1. Giovannucci E, Harlan DM, Archer MC, et al. Diabetes and cancer: a consensus report. CA Cancer J Clin. 2010;60(4):207-221. doi:10.3322/caac. 20078

2. Zimmet P, Alberti KG, Shaw J. Global and societal implications of the diabetes epidemic. Nature. 2001;414(6865):782-787. doi:10.1038/ 414782a

3. Vigneri P, Frasca F, Sciacca L, Pandini G, Vigneri R. Diabetes and cancer. Endocr Relat Cancer. 2009;16(4):1103-1123. doi:10.1677/ ERC-09-0087

4. Renehan A, Smith U, Kirkman MS. Linking diabetes and cancer: a consensus on complexity. Lancet. 2010;9733(375):2201-2202. doi:10.1016/S0140-6736(10)60706-4

5. Wu C-Y, Lin J-T. The changing epidemiology of Asian digestive cancers: from etiologies and incidences to preventive strategies. Best Pract Res Clin Gastroenterol. 2015;29(6):843-853. doi:10.1016/j.bpg.2015.09.016

6. Federation ID. IDF Diabetes Atlas Ninth edition. Available from: https://diabetesatlas.org/en/. Accessed 2019.

7. Ferlay J, Soerjomataram I, Dikshit R, et al. Cancer incidence and mortality worldwide: sources, methods and major patterns in GLOBOCAN 2012. Int $J$ Cancer. 2015;136(5):E359-E386. doi:10. $1002 /$ ijc. 29210

8. de Jong RG, Peeters PJ, Burden AM, et al. Gastrointestinal cancer incidence in type 2 diabetes mellitus; results from a large population-based cohort study in the UK. Cancer Epidemiol. 2018;54:104-111. doi:10.1016/ j.canep.2018.04.008
9. Chiu -C-C, Huang -C-C, Chen Y-C, et al. Increased risk of gastrointestinal malignancy in patients with diabetes mellitus and correlations with anti-diabetes drugs: a nationwide population-based study in Taiwan. Intern Med. 2013;52(9):939-946. doi:10.2169/internalmedicine. 52.8276

10. Ben Q, Xu M, Ning X, et al. Diabetes mellitus and risk of pancreatic cancer: a meta-analysis of cohort studies. Eur J Cancer. 2011;47 (13):1928-1937. doi:10.1016/j.ejca.2011.03.003

11. Chen H-F, Chen P, Li C-Y. Risk of malignant neoplasm of the pancreas in relation to diabetes: a population-based study in Taiwan. Diabetes Care. 2011;34(5):1177-1179. doi:10.2337/dc10-2006

12. Campbell PT, Deka A, Jacobs EJ, et al. Prospective study reveals associations between colorectal cancer and type 2 diabetes mellitus or insulin use in men. Gastroenterology. 2010;139(4):1138-1146. doi: $10.1053 /$ j.gastro. 2010.06 .072

13. Wang C, Wang X, Gong G, et al. Increased risk of hepatocellular carcinoma in patients with diabetes mellitus: a systematic review and meta-analysis of cohort studies. Int $J$ Cancer. 2012;130 (7):1639-1648. doi:10.1002/ijc.26165

14. Nitipir C, Barbu MA, Orlov C, et al. Type II diabetes mellitus associated risk factor in the onset and evolution of digestive tract carcinoma. Rom Biotechnol Lett. 2019;24(1):140-146. doi:10.25083/ $\mathrm{rbl} / 24.1 / 140.146$

15. Ma T-M, Sun L-P, Dong -N-N, Sun M-J, Yuan Y. Protein expression trends of DNMT1 in gastrointestinal diseases: from benign to precancerous lesions to cancer. World J Gastrointest Oncol. 2019;11 (12):1141-1150. doi:10.4251/wjgo.v11.i12.1141

16. Kirk R. Gastrointestinal cancer: a new dawn for CT scans in colon screening? Nat Rev Clin Oncol. 2012;9(1):6. doi:10.1038/ nrclinonc.2012.154

17. Jiao F, Jin Z, Wang L, Wang L. Research and clinical applications of molecular biomarkers in gastrointestinal carcinoma (Review). Biomed Rep. 2013;1(6):819-827. doi:10.3892/br.2013.158

18. Kenner BJ, Chari ST, Cleeter DF, Go VLW. Early detection of sporadic pancreatic cancer: strategic map for innovation-a white paper. Pancreas. 2015;44(5):686. doi:10.1097/MPA.000000000 0000369

19. Huang Y-Q, Liang C-H, He L, et al. Development and validation of a radiomics nomogram for preoperative prediction of lymph node metastasis in colorectal cancer. $J$ Clin Oncol. 2016;34 (18):2157-2164. doi:10.1200/JCO.2015.65.9128

20. Iasonos A, Schrag D, Raj GV, Panageas KS. How to build and interpret a nomogram for cancer prognosis. J Clin Oncol. 2008;26 (8):1364-1370. doi:10.1200/JCO.2007.12.9791

21. Harding JL, Shaw JE, Peeters A, Cartensen B, Magliano DJ. Cancer risk among people with type 1 and type 2 diabetes: disentangling true associations, detection bias, and reverse causation. Diabetes Care. 2015;38(2):264-270. doi:10.2337/dc14-1996

22. Organization WH. Diabetes Mellitus: Report of a WHO Study Group [Meeting Held in Geneva from 11 to 16 February 1985]. WHO; 1985.

23. Taghizadeh N, Vonk JM, Boezen HM. Lifetime smoking history and cause-specific mortality in a cohort study with 43 years of follow-up. PLoS One. 2016;11(4). doi:10.1371/journal.pone.0153310

24. Sauerbrei W, Boulesteix A-L, Binder H. Stability investigations of multivariable regression models derived from low-and high-dimensional data. J Biopharm Stat. 2011;21(6):1206-1231. doi:10.1080/10543406.2011.629890

25. Harrell FE, Califf RM, Pryor DB, Lee KL, Rosati RA. Evaluating the yield of medical tests. JAMA. 1982;247(18):2543-2546. doi:10.1001/ jama.1982.03320430047030

26. Harrell FE Jr, Lee KL, Mark DB. Multivariable prognostic models: issues in developing models, evaluating assumptions and adequacy, and measuring and reducing errors. Stat Med. 1996;15(4):361-387. doi:10.1002/(SICI)1097-0258(19960229)15:4<361::AID-SIM168>3. $0 . \mathrm{CO} ; 2-4$ 
27. Vickers AJ, Cronin AM, Elkin EB, Gonen M. Extensions to decision curve analysis, a novel method for evaluating diagnostic tests, prediction models and molecular markers. BMC Med Inform Decis Mak. 2008;8(1):53. doi:10.1186/1472-6947-8-53

28. Lee J, Lee SH, Hur KY, Woo SY, Kim SW, Kang WK. Statins and the risk of gastric cancer in diabetes patients. BMC Cancer. 2012;12:596. doi:10.1186/1471-2407-12-596

29. Cheng K-C, Chen Y-L, Lai S-W, Tsai P-Y, Sung F-C. Risk of esophagus cancer in diabetes mellitus: a population-based case-control study in Taiwan. BMC Gastroenterol. 2012;12:177. doi:10.1186/1471-230X-12-177

30. Boursi B, Finkelman B, Giantonio BJ, et al. A clinical prediction model to assess risk for pancreatic cancer among patients with new-onset diabetes. Gastroenterology. 2017;152(4):840-850. e843. doi:10.1053/j.gastro.2016.11.046

31. Hsieh M-H, Sun L-M, Lin C-L, et al. Development of a prediction model for colorectal cancer among patients with type 2 diabetes mellitus using a deep neural network. J Clin Med. 2018;7(9):277. doi: $10.3390 / \mathrm{jcm} 7090277$

32. Hsieh MH, Sun L-M, Lin C-L, Hsieh M-J, Hsu C-Y, Kao C-H. Development of a prediction model for pancreatic cancer in patients with type 2 diabetes using logistic regression and artificial neural network models. Cancer Manag Res. 2018;10:6317. doi:10.2147/ CMAR.S180791

33. Zheng J, Zhao M, Li J, et al. Obesity-associated digestive cancers: a review of mechanisms and interventions. Tumour Biol. 2017;39 (3):1010428317695020. doi:10.1177/1010428317695020

34. Dong Y, Zhou J, Zhu Y, et al. Abdominal obesity and colorectal cancer risk: systematic review and meta-analysis of prospective studies. Biosci Rep. 2017;37(6). doi:10.1042/BSR20170945

35. Bhaskaran K, Douglas I, Forbes H, dos-Santos-Silva I, Leon DA, Smeeth L. Body-mass index and risk of 22 specific cancers: a population-based cohort study of $5 \cdot 24$ million UK adults. Lancet. 2014;384(9945):755-765. doi:10.1016/S0140-6736(14) $60892-8$
36. Renehan AG, Tyson M, Egger M, Heller RF, Zwahlen M. Body-mass index and incidence of cancer: a systematic review and meta-analysis of prospective observational studies. Lancet. 2008;371 (9612):569-578. doi:10.1016/S0140-6736(08)60269-X

37. Feng R-M, Zong Y-N, Cao S-M, Xu R-H. Current cancer situation in China: good or bad news from the 2018 global cancer statistics? Cancer Commun (Lond). 2019;39(1):22. doi:10.1186/s40880-019-0368-6

38. Shi K, Sun Y. Manual of Medical Oncology (Sixth Edition). China: People's Medical Publishing House; 2014.

39. Hartgrink HH, Jansen EPM, Grieken NCTV, Velde CJHVD. Gastric cancer. Lancet. 2009;374(9688):477-490. doi:10.1016/S0140-6736(09) 60617-6

40. Pennathur A, Gibson MK, Jobe BA, Luketich JD. Oesophageal carcinoma. Lancet. 2013;381(9864):400-412. doi:10.1016/S01406736(12)60643-6

41. Siegel R, Ward E, Brawley O, Jemal A. The impact of eliminating socioeconomic and racial disparities on premature cancer deaths. $C A$ Cancer J Clin. 2011;61(4):212-236. doi:10.3322/caac.20121

42. Cha JM, Jeun JW, Pack KM, Lee JI, Shin WC. Risk of sedation for diagnostic esophagogastroduodenoscopy in obstructive sleep apnea patients. World J Gastroenterol. 2013;19(29):4745-4751. doi:10.3748/wjg.v19.i29.4745

43. Seinel L, Reinikainen P, Ahvenainen J. Effect of upper gastrointestinal endoscopy on cardiopulmonary changes in very old patients. Arch Gerontol Geriatr. 2003;37(1):25-32.

44. Collins GS, Reitsma JB, Altman DG, Moons KG. Transparent reporting of a multivariable prediction model for individual prognosis or diagnosis (TRIPOD): the TRIPOD statement. Br J Surg. 2015;102 (3):148-158. doi:10.1002/bjs.9736

45. Van Calster B, Vickers AJ. Calibration of risk prediction models: impact on decision-analytic performance. Med Decis Making. 2015;35(2):162-169. doi:10.1177/0272989X14547233

46. Localio AR, Goodman S. Beyond the usual prediction accuracy metrics: reporting results for clinical decision making. Ann Intern Med. 2012;157 (4):294-295. doi:10.7326/0003-4819-157-4-201208210-00014

\section{Publish your work in this journal}

Diabetes, Metabolic Syndrome and Obesity: Targets and Therapy is an international, peer-reviewed open-access journal committed to the rapid publication of the latest laboratory and clinical findings in the fields of diabetes, metabolic syndrome and obesity research. Original research, review, case reports, hypothesis formation, expert opinion and commentaries are all considered for publication. The manuscript management system is completely online and includes a very quick and fair peer-review system, which is all easy to use. Visit http://www.dovepress.com/testimonials.php to read real quotes from published authors.

Submit your manuscript here: https://www.dovepress.com/diabetes-metabolic-syndrome-and-obesity-targets-and-therapy-journal 